\title{
PRÁTICAS PEDAGÓGICAS REPRODUTORAS DE DESIGUALDADES: A SUB- REPRESENTAÇÃO DE MENINAS ENTRE ALUNOS SUPERDOTADOS
}

\author{
Ana Paula Poças Zambelli dos Reis \\ Universidade Católica de Brasília \\ Candido Alberto Gomes \\ Universidade Católica de Brasília
}

\begin{abstract}
Resumo: Muitos indicadores do Brasil e da América Latina mostram que ambos estão muito próximos da meta de paridade de gêneros da Educação para Todos. Entretanto, esmiuçando as estatísticas, encontram-se nichos nos quais as meninas são tratadas diferentemente, com base em preconceitos e estereótipos. Esse é o caso de um sistema de ensino em que as alunas são sub-representadas no seu Programa de Atendimento ao Aluno com Altas Habilidades/ Superdotação. A presente pesquisa investigou os critérios para identificar e encaminhar esses alunos. Com base em dados especialmente tabulados, foi selecionada a área geográfica com a menor representação de alunas, onde se realizaram entrevistas semiestruturadas com os profissionais do ensino regular, responsáveis pela indicação dos alunos, e com os profissionais do Programa. Após cada entrevista, foi entregue um formulário, em forma de check-list, com as características e/ou comportamentos que podem ser evidenciados nos alunos e nas alunas identificados como superdotados. A análise revelou que a subestimativa dos talentos femininos ocorre na seleção e na indicação de discentes pelos professores do ensino regular, quando as meninas são vistas pelas lentes de estereótipos, com a internalização de imagens de inferioridade pelas/os próprias/os professoras/es, em ampla maioria mulheres. Entretanto, os professores e os psicólogos do Programa evidenciaram ter compreensão da paridade de gênero e do conceito de altas habilidades/superdotados, esse coerente com a literatura. Assim, a sub-representação de meninas surge antes da porta de entrada, devendo os professores do ensino regular ser adequadamente preparados para realizar as indicações.
\end{abstract}

Palavras-chave: gênero; estereótipo; superdotação; educação especial.

Copyright $\odot 2011$ by Revista Estudos Feministas. 
Por que um programa de altas habilidades/superdotação tem ampla predominância de meninos, quando as meninas são maioria no total de matrícula do ensino regular? Embora aparentemente o Brasil não tenha tão graves problemas de paridade de gênero na educação, conforme uma das Metas de Desenvolvimento do Milênio e do pacto de Educação para Todos, diferenças sutis podem desvelar fatos inconvenientes. Sabe-se que os processos de seleção de alunos refletem estereótipos e caminhos de privilégio sociocultural e socioeconômico. Nessas situações, profissionais são chamados a tomar decisões de impactos, não raro irreversíveis, sobre a vida posterior de crianças e adolescentes. Aparentemente muitas meninas deixaram de ser escolhidas para ingresso no Programa por não terem certas manifestações estereotipadas, impedindo-as de desfrutarem de oportunidades educacionais enriquecedoras, em horário suplementar, conforme as políticas do respectivo sistema estadual de ensino.

Com efeito, os mundos "azul" e "rosa" compreendem incentivos diferenciados. A construção da identidade pessoal não se efetua sob as mesmas condições para meninos e meninas. É preciso entender como o gênero molda nossos pensamentos, linguagem e ações, evitando que se inviabilizem as medidas para igualdade no contexto da construção da cidadania. Com base em definições do que é ser homem e/ou mulher, edifica-se um sistema de discriminação e exclusão entre os sexos pautado em estereótipos. Apresentados como categorias opostas, excludentes e hierarquizadas, o feminino e o masculino encontram eco nas instituições sociais, como família e escola, que perpetuam valores históricos e culturais.

Por isso mesmo, as divisões sociais geradas, reforçadas e mantidas pela escola afetam não somente o desempenho educacional de alunas, mas também suas oportunidades e perspectivas de vida. Embora nas últimas décadas as oportunidades de carreiras para mulheres tenham se expandido enormemente, ainda persistem notáveis desigualdades no mercado de trabalho.

A escola, apontada como uma instituição que reproduz as diferenças sociais, impondo valores e padrões culturais discriminatórios, precisa assumir o seu papel de agente de mudança, deixando de lado práticas pedagógicas que silenciam as desigualdades e corroboram a discriminação diluída no cotidiano escolar, sob pena de trair seus princípios básicos de igualdade.

Por isso a pesquisa em foco preocupa-se com os motivos que podem contribuir para a reprodução da desigualdade de gênero no âmbito educacional, tendo em vista: 1) investigar se os sinais manifestos de superdotação são mais detectados nos alunos do que nas alunas e por quê; 2) apontar os critérios utilizados pelos professores para identificar comportamentos de superdotação, bem como as suas variações por gênero; 3) identificar, na percepção de professores e psicólogos, os motivos relacionados à sub-representação feminina no Programa de Atendimento ao Aluno com Altas Habilidades/Superdotação.

\section{Superdotação e diferenças de gênero}

O conceito de gênero possui uma historicidade importante para compreender a construção dos sentidos e dos significados relacionados à feminilidade e à masculinidade, podendo justificar a forma como hierarquizamos e reproduzimos a dominação masculina. No âmbito da sociologia da educação, o entendimento desse conceito tem se mostrado muito útil para iluminar os mais diversos processos: as diferenças de trajetórias escolares entre meninos e meninas; as relações entre escola e família; as escolhas de carreiras diferenciadas por sexo; a indisciplina de alunos e alunas; as interações e brincadeiras entre as crianças; e a presença majoritária de mulheres na categoria docente.

1 Carol ADAMS, 2004. 
Os brinquedos das meninas, como as bonecas, com frequência se limitam ao campo de atividades maternais e estimulam as interações verbais, enquanto os brinquedos dos meninos, muito mais numerosos e centrados em atividades diversas, ligadas à agressão, aventura, mecânica, movimento e construção, permitem a eles, menos restritos em seus movimentos, construírem-se num espaço cuja liberdade lhes propicia desenvolver e amadurecer a sua autoconfiança, eventualmente distanciando-se da escola. Eles aprendem a se afirmar fora da escola e contra ela. Desse modo, a transgressão das regras faz parte dos valores associados à socialização dos meninos, o que tende a torná-los mais visíveis na escola. ${ }^{2}$

Uma questão apontada como central é a diferença de campos de estudo na educação superior, com influência direta em seus empregos, na renda e nos papéis que as mulheres poderão desempenhar na sociedade. ${ }^{3}$ Seriam essas diferenças reflexo das preferências de gênero ou uma consequência mais direta de estereótipos?

O magistério se constituiu num gueto cor-de-rosa, isto é, numa ocupação predominante ou exclusivamente feminina, primeiro, pelas afinidades entre os papéis de mãe e professora, o que levaria a estruturar-se nas escolas um ambiente predominantemente feminino, mais favorável ao ajustamento das alunas; e, segundo, por ser uma carreira que permite, em termos, ou permitia, o desempenho simultâneo do papel de cuidar da casa e da família. Não por acaso, meninas são mais concentradas e disciplinadas, "mais escolares", reforçando o estereótipo de gênero; contudo, elas enfrentam o chamado "teto de vidro": apesar das notas mais altas, são desencorajadas a buscar as áreas mais bem remuneradas do mercado de trabalho, como as ciências, as tecnologias e as engenharias, não conseguindo traduzir o aproveitamento escolar em conquistas ocupacionais. ${ }^{4}$

As diversidades entre gêneros igualmente se verificam nas preferências por estilo de aprendizagem, conforme apontado pelo Programa Internacional de Avaliação de Alunos - PISA, que examinou o desempenho escolar de alunos de 15 anos de idade, em 2003, em 42 países, constatando que, em relação à leitura, o desempenho das alunas foi superior ao dos meninos em todos os países; porém, na Matemática, os alunos tiveram melhores resultados do que as meninas em 34 dos 42 países; já em Ciências o desempenho de ambos foi equilibrado. ${ }^{5}$

Maia-Pinto ${ }^{6}$ aponta em sua pesquisa que "há o predomínio da noção de que pessoas do gênero masculino têm mais facilidade nas áreas que requerem habilidades físicas e técnicas, ao passo que as do gênero feminino têm melhor desempenho nas áreas de domínio artístico, social e afetivo", desenvolvendo comportamentos estereotipados e vieses de identificação. Por outro lado, evidências de que as meninas estão superando os meninos na escolarização nem sempre indicam uma reversão da desigualdade de gênero. Os resultados educacionais tendem a não compensar desigualdades nos mercados de trabalho, que continua a favorecer os homens. Há muitos exemplos indicando que as alunas não conseguem converter suas vantagens acadêmicas em maior igualdade noutras esferas. Para terem sucesso, as mulheres muitas vezes precisam atingir níveis bem mais altos do que os homens. ${ }^{7}$

Povey $^{8}$ chama a atenção para o fato de que, embora as alunas tenham melhor desempenho na escola, o salário médio dos homens ainda é maior, o que pode ser

${ }^{2}$ Christian BAUDELOT e Roger ESTABLET, 2006 e 2007.

3 UNESCO, 2004.

${ }^{4}$ Candido Alberto GOMES, 2005.

${ }^{5}$ ORGANIZATION FOR ECONOMIC CO-OPERATION AND DEVELOPMENT, 2004.

${ }^{6}$ Renata Rodrigues MAIA-PINTO, 2002, p. 97.

7 UNESCO, 2004.

${ }^{8}$ Hilary POVEY, 2004. 
facilmente explicado pelas barreiras que as mulheres enfrentam por serem ainda responsáveis, de modo desproporcional, tanto pelo cuidado com os filhos quanto pelas tarefas domésticas, além de enfrentarem a subestimativa do seu desempenho acadêmico e suas capacidades emocionais. A empreitada, então, não se encerra com o oferecimento de iguais oportunidades de acesso à educação: é preciso garantir condições equivalentes para que todos os alunos permaneçam no sistema e sejam bem-sucedidos. Atingir igualdade de gênero em educação implica igualdade de oportunidades no processo de aprendizagem e de resultados dentro e fora da escola, inclusive no trabalho, pois, embora esse não faça parte diretamente do campo educacional, é fortemente marcado pelos efeitos da educação. ${ }^{9}$

Cabe esclarecer que paridade de gênero e igualdade de gênero não significam a mesma coisa em educação. O primeiro, paridade, é um conceito puramente numérico que implica ter a mesma proporção de meninos e meninas no sistema educacional, participando dos seus diversos ciclos segundo os grupos etários. Já a igualdade, mais difícil de medir e alcançar, significa ter meninos e meninas desfrutando das mesmas vantagens em termos de acesso e tratamento educacionais. Por isso mesmo Virgolim ${ }^{10}$ ressalta que a verdadeira equidade está presente quando todos os alunos têm igual acesso às oportunidades, de tal modo que oferecer o mesmo currículo a todos os alunos pode significar a negativa das diversidades.

Maia-Pinto, ${ }^{11}$ por sua vez, ressalta dados que apontam o dobro do número de alunos do gênero masculino em relação ao número de alunas atendidos num programa especial e que a falta de controle sobre os fatores sociais, culturais e ambientais influencia o desenvolvimento das habilidades dos indivíduos do gênero feminino. As barreiras enfrentadas por elas podem inibir o seu potencial, possivelmente superior, tornando-se necessárias providências para minimizar essas barreiras.

O conceito de superdotação esteve por muito tempo associado ao de inteligência. A mudança de uma visão unidimensional para outra, multidimensional, tem possibilitado, além de definições mais amplas de inteligência, uma revisão nas formas de identificação do indivíduo superdotado. Alencar e Fleith ${ }^{12}$ afirmam que as definições propostas nas últimas décadas têm enfatizado que a superdotação não seria um atributo do indivíduo, e sim resultado da interação do indivíduo com o seu ambiente, sendo "um conceito ou construto psicológico a ser inferido a partir de uma constelação de traços ou características de uma pessoa". Contudo, em relação à superdotação feminina, as novas teorias da inteligência pouco ou nada dizem, sendo necessárias pesquisas substanciais na área.

Os programas de atendimento a superdotados e talentosos são frequentemente questionados a respeito da sua relevância e eficiência, podendo gerar certo ceticismo a respeito de seus benefícios; ${ }^{13}$ entretanto, a validade do atendimento específico para os superdotados é uma discutida questão de política pública que ultrapassa os propósitos deste trabalho. Este não se propõe a avaliar os impactos de tais programas, mas verificar por que, no caso em tela, as meninas são sub-representadas. No entanto, Maia-Pinto ${ }^{14}$ sugere que seja feita uma redefinição na educação de superdotados, não direcionando práticas exclusivamente para esses alunos, mas propiciando estratégias capazes de nutrir potenciais e talentos de vários outros alunos. Segundo a autora, um dos objetivos do modelo

\footnotetext{
9 UNESCO, 2004.

${ }^{10}$ Angela Mágda Rodrigues VIRGOLIM, 2007.

11 MAIA-PINTO, 2002.

12 Eunice Soriano de ALENCAR e Denise de Souza FLEITH, 2001, p. 52.

${ }^{13}$ MAIA-PINTO, 2002.

14 MAIA-PINTO, 2002.
}

506 Estudos Feministas, Florianópolis, 19(2): 503-519, maio-agosto/2011 
de enriquecimento escolar é estabelecer uma parceria entre professores de sala regular e de sala de recursos, minimizando as ações negativas diante de alunos não participantes do Programa. ${ }^{15}$

De acordo com Kerr, ${ }^{16}$ enquanto novas teorias aperfeiçoam o entendimento de inteligência, torna-se cada vez mais crítica a tarefa de identificar a superdotação feminina, uma vez que essas teorias pouco ou nada dizem sobre os gêneros. Além disso, as desigualdades de gênero, originadas histórica e culturalmente, contribuem para construir barreiras internas e externas que, com frequência, coíbem meninas talentosas de mostrarem todo o seu potencial acadêmico. Certos traços de personalidade, como iniciativa e independência, que poderiam favorecer seu desempenho, tendem a não ser enfatizados.

Essa espécie de desequilíbrio e desigualdade de gênero é uma preocupação em qualquer época, mas tem tomado significado maior à medida que a sociedade experimenta uma mudança de paradigmas. Kerr ${ }^{17}$ afirma que os conflitos de valores sobre os papéis das mulheres passaram a permear não apenas a sociedade, mas a educação e a pesquisa. E ressalta que nós, pesquisadores, temos o que parece uma enorme tarefa: descobrir as barreiras para o sucesso das mulheres superdotadas e encontrar meios de superá-las.

Se ainda permanece o sexismo na sociedade brasileira, isso também se deve à maneira como se educam filhos, alunos, maridos etc. Sabemos que são mães, avós, professoras, babás e esposas a parte mais importante nesse processo educativo. Por isso Benevides, ${ }^{18}$ militante feminista, mãe de dois rapazes e uma menina, alerta para como, de alguma forma, as mulheres internalizam referências e valores. Certa vez, ela conta, chamei minha filha, quando tinha 14 ou 15 anos, e disse: "Marina, você não gostaria de aprender a cozinhar? Eu vou te ensinar, nós podemos passar os sábados na cozinha, que tal?". Ela respondeu: "Você vai ensinar também para o Daniel e para o André?". Eu levei um susto e falei: "Não, é claro". Ela então encerrou com seu melhor sorriso: "Ah, então eu também não quero. Ou você ensina aos três, ou a ninguém. Eu não gosto de cozinhar, no dia em que precisar eu aprendo".

Segundo Wechsler, ${ }^{19}$ a questão do gênero é tão sutil que sequer nos damos conta de que, ao darmos uma boneca para nossa filha, estamos perpetuando a ideia de que a menina deverá "ser bonita como uma boneca e tomar conta de alguém como de um filho". A autora ${ }^{20}$ aponta, ainda, "o medo do sucesso, o sentimento de engano e o complexo de Cinderela" como as principais barreiras internas enfrentadas pela mulher. Este último, também conhecido por "desejo de ser salva", é descrito como "uma necessidade, desde muito cedo cultivada na mulher, de ser cuidada por alguém [...], de ser salva", expressando a vontade da mulher de encontrar alguém mais forte, capaz de sustentá-la e protegê-la. Efetivamente, estudos citados pela autora apontam para o fato de que a energia e o tempo dedicados para cuidar do lar e dos filhos limitam a mulher nas suas manifestações criativas. A forte influência, exercida na nossa cultura pelo casamento e pela maternidade, sustenta a dependência e a fragilidade feminina, comumente descritas nas histórias infantis, que nos fazem crer que a realização pessoal virá por intermédio do marido e dos filhos.

Entender as representações da divisão social dos sexos e de outros sistemas de dominação torna-se atividade-meio para a transformação das relações sociais. Entre as narrativas e as intervenções que promovem a cidadania e a democracia, as relações de

\footnotetext{
${ }^{15}$ FLEITH, 1999; e MAIA-PINTO, 2002.

${ }^{16}$ Barbara KERR, 2000.

17 KERR, 2000.

${ }_{18}$ Maria Vitória BENEVIDES, 2004, p. 97.

${ }^{19}$ Solange Muglia WECHSLER, 1993.

${ }^{20}$ WECHSLER, 1993, p. 109.
} 
gênero vêm engrossar as múltiplas facetas das desigualdades sociais. Nesse sentido, Carvalho $^{21}$ aponta o papel fundamental da educação, começando na família como processo de socialização, em duas dimensões: na transmissão de uma herança cultural (social) e na formação e aquisição de conhecimentos, habilidades e valores (individual). A complexidade das relações que se estabelecem desde muito cedo com a criança encontra, quer seja em casa, com a família, quer seja na escola, um ambiente preparado para efetuar distinções, promovendo desigualdades entre homens e mulheres. É preciso ver que, por trás das diferenças entre os gêneros, está a construção dos significados das relações de poder socialmente constituídos. As relações de gênero são, antes de mais nada, relações sociais em que os significados e os símbolos vão além dos corpos e dos sexos, subsidiando noções de ideias e valores.

\section{Metodologia}

Constatada a significativa e constante desigualdade de gênero numa rede escolar pública urbana, cujo nome será resguardado por questão de ética, foi realizado manualmente o levantamento de dados acerca do número de alunas e alunos participantes das salas de recursos do Programa de Atendimento ao Aluno com Altas Habilidades/ Superdotação, nos últimos cinco anos (2002-2007), com base nas fichas de controle de registro dos alunos atendidos. Conforme a Tabela 1, as desigualdades de gênero se manifestam em todas as áreas geográficas, com a matrícula das meninas representando menos de um terço da matrícula dos meninos.

Selecionou-se, então, a área geográfica onde existe menor representação de alunas durante a maior parte do período observado, supondo-se que o fenômeno seja mais intenso onde as desigualdades de gênero são maiores (Tabela 2). Cabe informar que a população dessa área é socioeconomicamente privilegiada, apresenta Índice de Desenvolvimento Humano - IDH igual a 0,936, enquanto o da Unidade Federativa é de 0,849. Optou-se, assim, por uma amostra intencional, composta de casos ricos em informações para o estudo, uma vez que o aprofundamento provavelmente se efetuará melhor onde as diferenças forem estatisticamente maiores ${ }^{22}$ Sendo de caráter exploratório, a presente pesquisa não reivindica representatividade estatística.

\footnotetext{
${ }^{21}$ Marília Pinto de CARVALHO, 2004

22 Michael Quinn PATTON, 2000.
} 


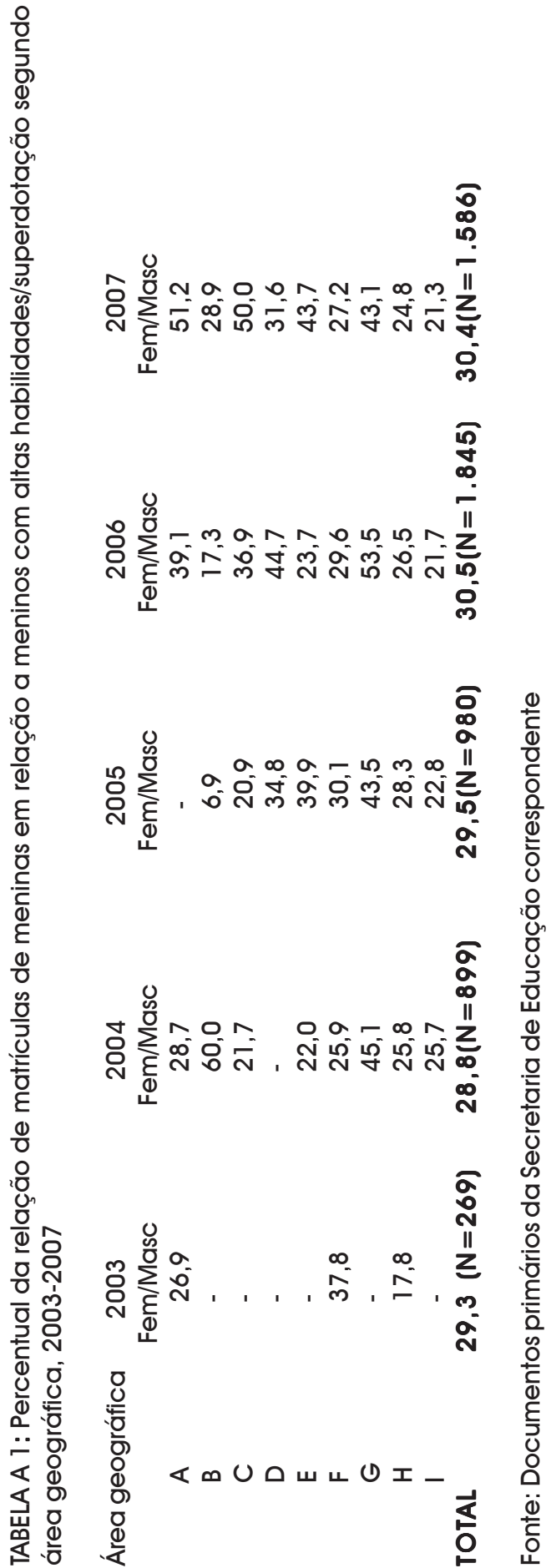

Estudos Feministas, Florianópolis, 19(2): 503-519, maio-agosto/2011 509 


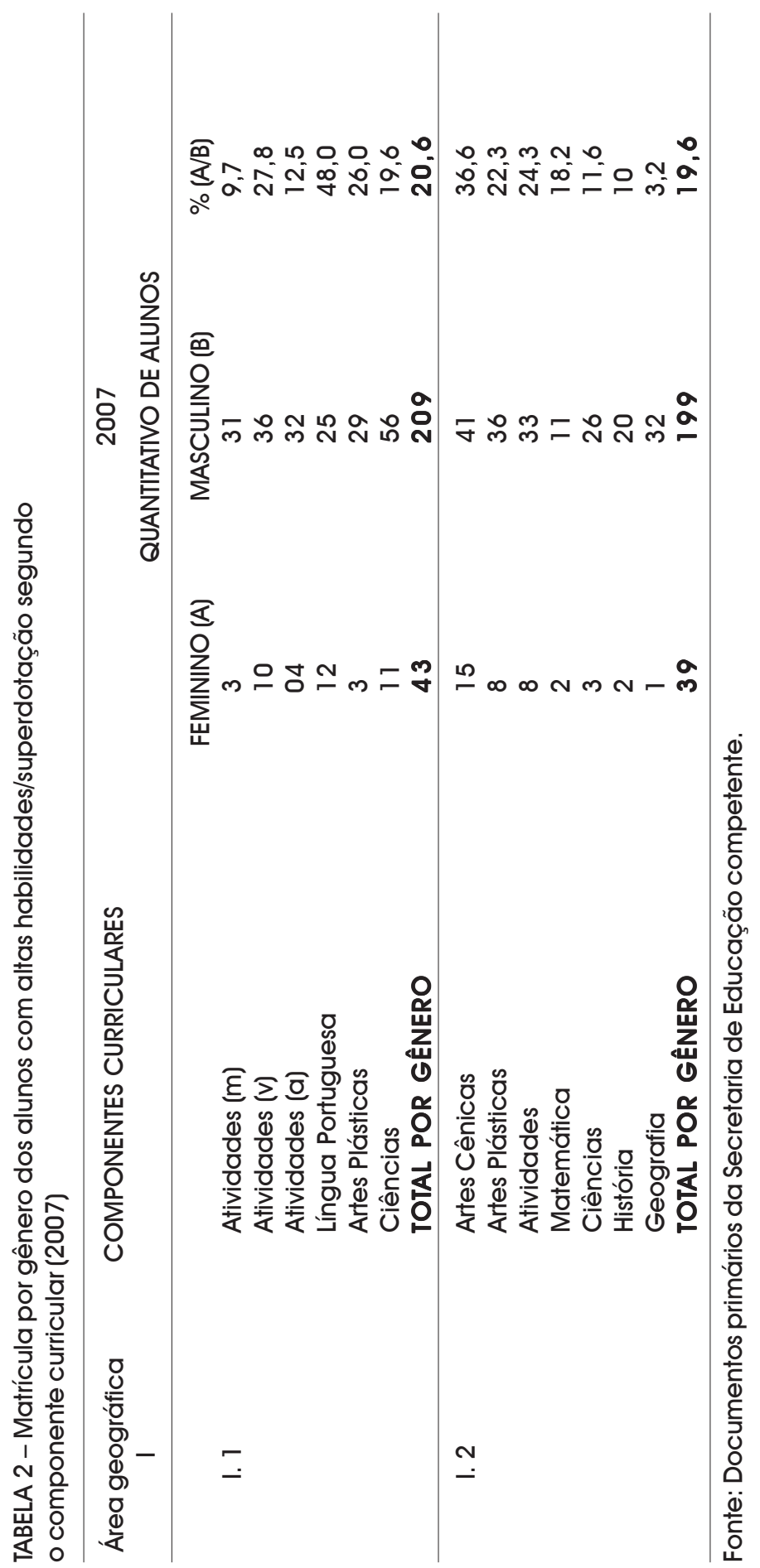

510 Estudos Feministas, Florianópolis, 19(2): 503-519, maio-agosto/2011 
Escolhida a área, iniciou-se a realização de entrevistas individuais, semiestruturadas, com uma amostra aleatória simples de $20 \%$ da população dos professores responsáveis pela indicação dos alunos $(n=8)$, mais todos os professores e psicólogos do Programa na área geográfica selecionada, responsáveis pelo diagnóstico e pela permanência desses alunos $(\mathrm{N}=8)$. Após a entrevista, foi entregue um formulário, com a estrutura de check-list, com as características e/ou comportamentos que podem ser evidenciados nos alunos e nas alunas possivelmente identificados como superdotados para que os respondentes assinalassem os mais frequentes para cada gênero. O formulário tem como base a escala de características constante do instrumento oficial utilizado no processo de identificação e encaminhamento de alunos ao Programa.

O presente estudo coletou ao todo dados de 16 profissionais, sendo quatro do sexo masculino e doze do feminino. Dois declararam ter de três a cinco anos de serviço; três declararam ter de cinco a 10 anos; e 11 (68,75\%) informaram ter mais de 10 anos de serviço. Com relação a ter "experiência" no trabalho junto a alunos com altas habilidades/ superdotação, todos os oito profissionais (sete professores e uma psicóloga) das salas de recursos de Altas Habilidades/Superdotação afirmaram tê-la, enquanto os oito profissionais (sete professores e uma orientadora educacional) que atuam no ensino regular declararam não tê-la. Ao serem questionados sobre a participação em cursos, congressos e outros eventos na área de altas habilidades/superdotação, todos os oito profissionais que trabalham nas salas de recursos disseram já ter participado, enquanto que, dentre os do ensino regular, apenas um havia participado.

Sete entrevistados declararam ter curso de especialização (pós-graduação), sendo três em Altas Habilidades/Superdotação. Todos tinham curso superior, sendo um de Psicologia, um de Licenciatura Plena em Geografia, dois de Licenciatura Plena em História, dois de Licenciatura Plena em Ciências, dois de Licenciatura Plena em Artes Plásticas e oito de Pedagogia. Na formação de nível médio, seis declararam ter curso normal (magistério), um profissionalizante de outra área e o restante marcou "outros".

A organização e a análise dos dados da presente pesquisa se deram em dois momentos: no primeiro, a tabulação dos formulários e, no segundo, procedeu-se à análise de conteúdo das entrevistas. Os dados obtidos por meio das entrevistas são predominantemente descritivos, portanto, como técnica para compreender a mensagem presente nas falas dos entrevistados, foi utilizada a análise de conteúdo proposta por Bardin. ${ }^{23}$ Os dados do formulário foram tabulados e as medidas estatísticas descritivas calculadas por meio de programas computacionais. O material foi exaustivamente explorado a fim de garantir a compreensão dos conteúdos e das estruturas das mensagens, e a fidedignidade ao estudo.

\section{Resultados}

O formulário referido indicava, para cada característica/comportamento, duas categorias para os respondentes assinalarem no caso de meninos e meninas: "frequentemente" e "raramente". Para simplificar a apresentação dos dados, aparecem nas Tabelas 3 e 4 apenas os percentuais de respostas "frequentemente". Assim, se, por exemplo, surge o percentual de $75 \%$ numa célula das tabelas, significa que $75 \%$ dos respondentes marcaram "frequentemente" e os $25 \%$ restantes, "raramente". Os dados mostram que algumas das características/comportamentos são consideradas frequentes em ambos os gêneros pelos dois grupos de profissionais, do ensino regular e das salas de

${ }^{23}$ Laurence BARDIN, 1995. 
recursos. Outras características/comportamentos são consideradas frequentes em ambos os gêneros apenas pelos profissionais do ensino regular e outras apenas pelos profissionais das salas de recursos.

Num universo de 38 características/comportamentos, apenas cinco $(13,16 \%)$ foram consideradas frequentes por ambos os grupos de profissionais. Na percepção dos profissionais do ensino regular, apenas oito $(21,05 \%)$ características/comportamentos são frequentes nos dois gêneros, enquanto que, para os profissionais das salas de recursos, 25 $(65,78 \%)$ dessas características/comportamentos são frequentes tanto em meninos quanto em meninas. Em outras palavras, os profissionais do ensino regular reconhecem maior diferenciação entre meninos e meninas do que os profissionais das salas de recursos.

Verificou-se o consenso de que os alunos dos dois gêneros aprendem com rapidez, apresentam grande quantidade de informações, são curiosos, gostam de desafios e demonstram autoconfiança. Para os profissionais do ensino regular, destacam-se em comum o aborrecimento em face da rotina, a fluência verbal e a capacidade de influenciar o grupo. Os profissionais das salas de recursos ainda assinalaram flexibilidade de pensamento, originalidade, habilidade de pensamento imaginativo e capacidade de análise e síntese, entre outras. Esses dados, de modo geral, foram reafirmados pelos profissionais das salas de recursos, quando esses disseram não perceber diferenças significativas entre os gêneros.

Maia-Pinto e Fleith ${ }^{24}$ relatam pesquisa segundo a qual a maioria dos professores do ensino regular tem conhecimento superficial do conceito de superdotação e do processo de identificação, o que foi corroborado pelas entrevistas nesta investigação. Entretanto, relembra-se que são esses educadores os responsáveis pela seleção e pela recomendação dos alunos com comportamento de superdotação.

A Tabela 3 apresenta uma síntese das características/comportamentos mais frequentemente encontradas em meninos e meninas segundo os profissionais das salas de recursos. Para efeito de análise, foi considerado frequente acima de $75 \%$, o que corresponde à opinião de mais de 12 participantes num universo de 16 entrevistados. No caso dos meninos, com grande diferença em relação às meninas, figuram: abertura a novas experiências, novas ideias e sugestões externas; gostam de lidar com problemas abstratos/ complexos e propor soluções; capacidade de influenciar o grupo com suas ideias e opiniões (agem como líderes); e não ligam para as convenções. Já as meninas, também por ampla margem, foram consideradas com maior fluência verbal; maior capacidade de interpretar personagens, habilidade para imitar e/ou improvisar papéis; e com maior interesse por televisão, cinema e teatro.

As respostas da amostra de professores do ensino regular (Tabela 4) apontam duas

${ }^{24}$ MAIA-PINTO E FLEITH, 2002.

512 Estudos Feministas, Florianópolis, 19(2): 503-519, maio-agosto/2011 


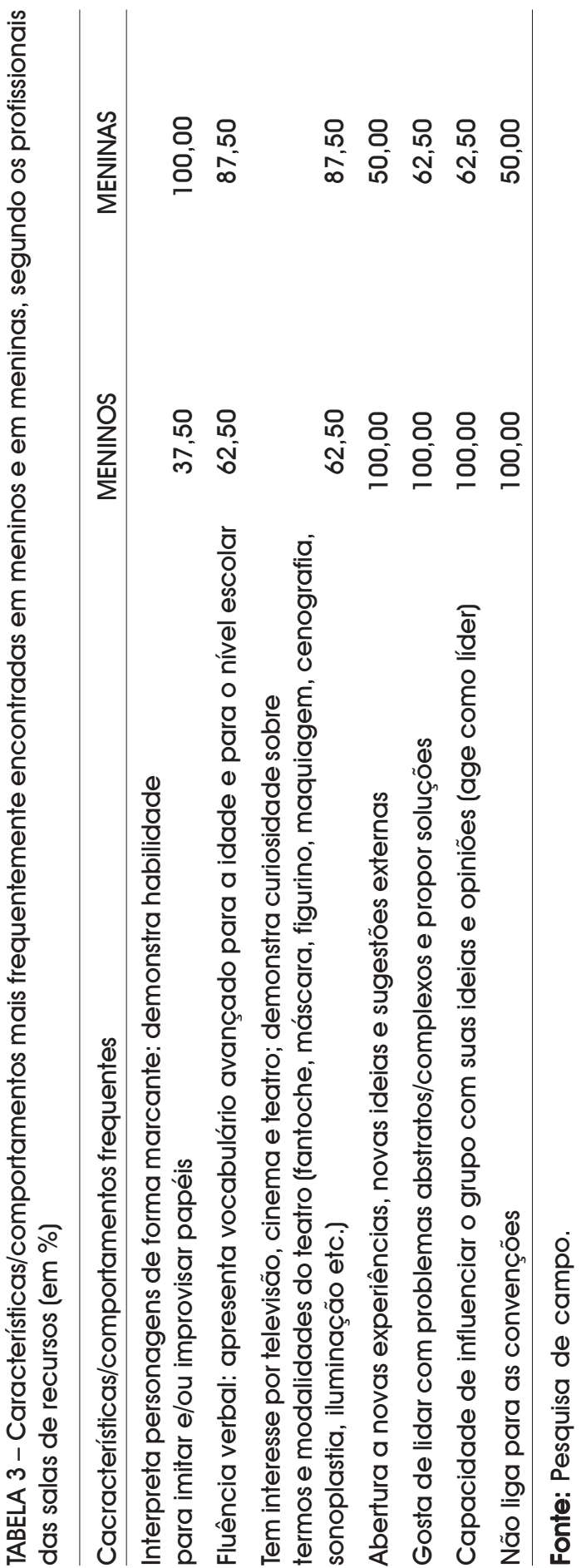

Estudos Feministas, Florianópolis, 19(2): 503-519, maio-agosto/2011 513 


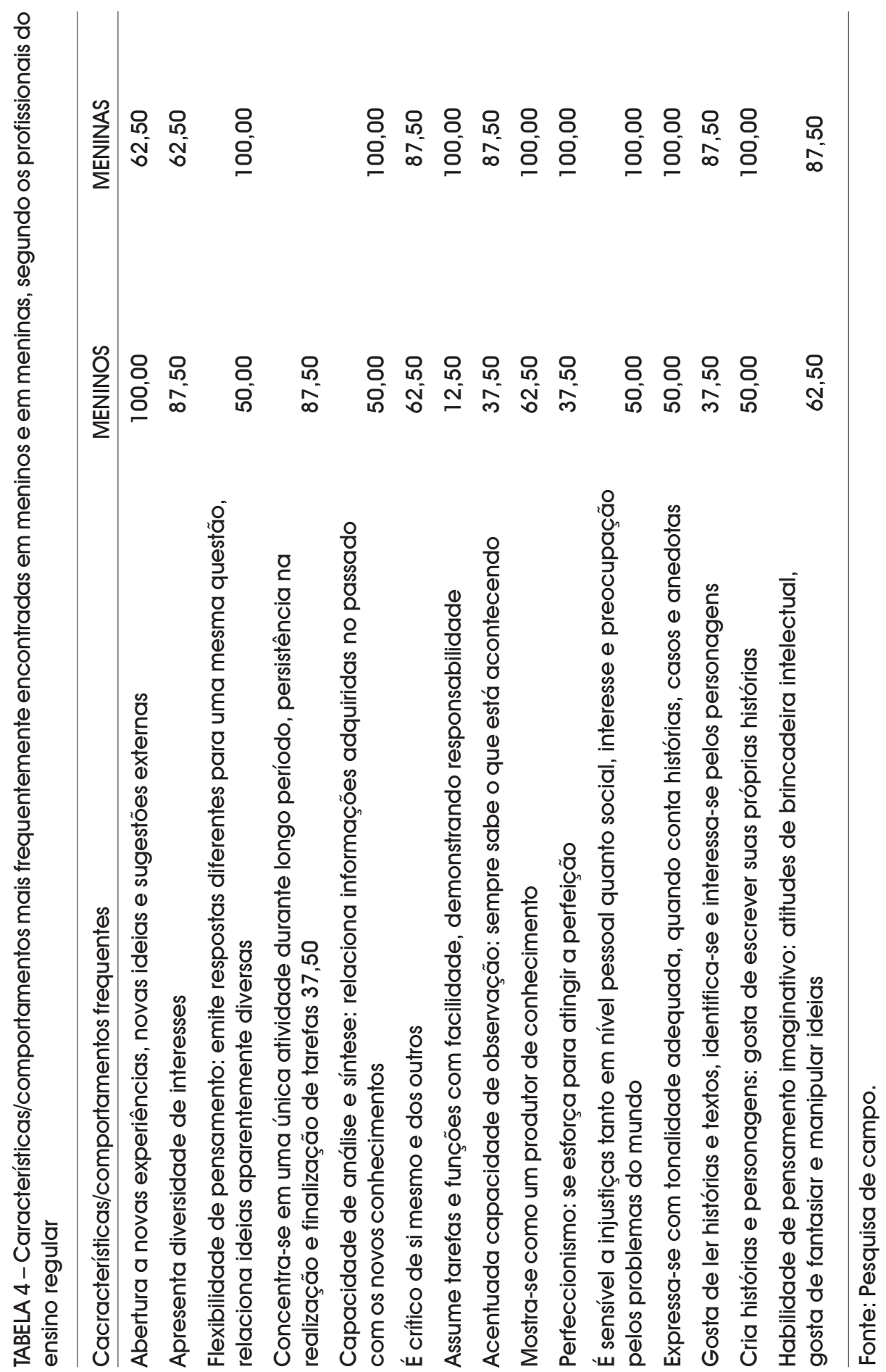

514 Estudos Feministas, Florianópolis, 19(2): 503-519, maio-agosto/2011 
características/comportamentos mais frequentes em meninos e 13 em meninas. Tais características/comportamentos coincidem com os componentes curriculares de maior interesse, segundo os respondentes: Língua Portuguesa e suas literaturas e Artes Cênicas com maior frequência para meninas (100\% e 93,75\%, respectivamente). Em contraste, Informática $(93,75 \%)$, Física $(93,75 \%)$, Matemática $(93,75 \%)$ e Química $(87,5 \%)$ foram assinaladas para os meninos. Tais dados reiteram a literatura, ou seja, o predomínio da visão de que pessoas do gênero masculino têm maior facilidade nos componentes curriculares exigentes de habilidades físicas e técnicas, ao passo que as do gênero feminino têm melhor desempenho nas áreas de domínio artístico, social e afetivo. ${ }^{25}$

Essa diferenciação foi também constatada na França por Baudelot e Establet, ${ }^{26} \mathrm{com}$ os rapazes predominando nos ramos de Matemática, Ciências e Tecnologia, enquanto as moças afluem em maior número às Humanidades. Desde cedo, os primeiros mostram maior aproveitamento em Matemática, ao passo que as últimas logo se distanciam, tomando a dianteira no idioma francês. Os autores atribuíram o interesse e o sucesso das meninas ao rigor gramatical e à obediência de regras formais. É bem verdade que a Matemática também possui normas rigorosas, porém o nível de abstração é muito maior, o que não seria uma capacidade "tipicamente feminina". Com isso, ao longo da escolarização, os/as alunos/as desenvolvem interesses diversos, incluindo a aversão das meninas à Matemática e às Ciências.

Embora haja uma série de explicações hipotéticas, tal afastamento envolve a maioria dos traços culturais que definem o modelo tradicional proposto às mulheres: maior interesse pelo conhecimento racional da natureza, menor interiorização dos valores de competição e incerteza mais intensa em relação ao investimento estritamente profissional. A instituição escolar explora esses traços que os alunos já trazem da socialização familiar, de tal modo que se aplicam duas leis não escritas: a vantagem inicial para as meninas e, depois, a vantagem para os meninos na competição escolar, que se prolonga ou se amplia ao longo da vida profissional.

As entrevistas semiestruturadas corroboraram as respostas aos formulários. Quatro participantes, sendo um do ensino regular e três das salas de recursos, afirmaram não perceber muitas diferenças entre os gêneros. Entretanto, duas outras participantes fizeram referência à feminilização do magistério como fator que pode influir na seleção de possíveis superdotados. Os estereótipos correntes aparecem nas falas a seguir, inclusive sobre a maior visibilidade dos meninos em sala de aula, em detrimento de uma suposta maior empatia entre professoras e alunas:

Eu acho... até porque nós, mulheres, estamos na gestão desse processo, eu sou mulher... (rsrsrs), talvez o olhar se volte mais para os meninos, porque a gente tem um número muito maior de mulheres [docentes], pelo menos de primeira a quarta série... Então, será que eu consigo ter sobre a menina um olhar diferenciado, eu acho que a gente se identifica com essa menina e, de repente, como a gente não se autoriza, não dá a essa menina autorização... (Professora do ensino regular)

Somos maioria na Secretaria, professoras, o que está implícito aí é uma repetição de padrão cultural... A gente é ensinada a valorizar, a enxergar mais o homem, e a gente termina repetindo esse padrão. (Professora da sala de recursos, grifo nosso)

Aquilo que poderia se constituir numa "vantagem" para as meninas, isto é, o elevado número de professoras incentivar mais as alunas, acaba por contribuir para beneficiar os

25 MAIA-PINTO, 2002

26 BAUDELOT E ESTABLET, 2007. 
meninos, em função da "repetição de padrão cultural", conforme a fala anterior, endossada por outros entrevistados nas declarações abaixo.

... Porque da menina se espera um comportamento padrão, então tudo que (sic) ela faz é muito natural... essa excepcionalidade é aceita com naturalidade. (Professor da sala de recursos)

Eu acho que o menino..., ele é mais autorizado a se expor. A menina não..., tem que ser mais quietinha, mais educadinha... se ela se expõe muito, é muito "saidinha", é muito exibida - isso é malvisto. O menino não, é porque ele é inteligente... Se, para o menino, eu ressalto uma característica que pode até ser interessante, para a menina já é negativa... culturalmente, socialmente, a gente autoriza o menino a isso e a menina não. (Professora do ensino regular)

Uma herança sociocultural de conformismo e obediência condiciona as expectativas de comportamento em relação às meninas e possivelmente as expectativas delas quanto a si mesmas. A elas cabe, conforme a tradição grega, o recolhimento ao gineceu, parte da casa reservada ao gênero feminino, ao passo que aos homens compete salientar-se, atreverse, aparecer, tomar iniciativas:

As meninas são questionadoras... mas com muito cuidado até em colocar isso, com medo de ser discriminadas... Não pode mostrar que sabe mais se ela quiser ser aceita pelo grupo. (Professora do ensino regular)

... A gente foi educada socialmente e historicamente para entender e prestar atenção. A habilidade da mulher era ficar em casa e cuidar das crianças. [...] A gente é educada para leitura e para o bordado. (Professora da sala de recursos)

As oportunidades para os indivíduos do gênero feminino continuam muitas vezes a serem determinadas pela noção do papel primordial da mulher dentro de casa e do cuidado com a família. Os valores que recebemos, definindo os perfis de comportamentos masculinos e femininos, sustentam a forte influência do casamento e da maternidade, impostos pela nossa cultura. Segundo Wechsler, ${ }^{27}$ a energia e o tempo dedicados a cuidar dos filhos limitam a mulher talentosa, que enfrenta inúmeros conflitos, barreiras externas e internas, como o medo de competir e arriscar-se à desaprovação social.

Embora estudem juntos, nas mesmas escolas e turmas, ambos levam um capital de experiências que os diferencia. O sexo, como a cor da pele, define uma identidade social imediata e evidente. O repertório virtual de expectativas sociais, orientando a educação de meninos e meninas desde cedo, até antes do nascimento, é o que se chama de estereótipo.

Com efeito, Alencar ${ }^{28}$ observa que uma análise das pesquisas realizadas nas últimas décadas chama a atenção para aspectos relacionados à dimensão emocional da superdotação. Dependendo do grau de inteligência, aliado a outras variáveis, como gênero, poderão ser percebidas dificuldades de ajustamento. Por sua vez, segundo Sabatella, ${ }^{29}$ "as meninas brilhantes, altamente verbais, curiosas e que gostam de discutir ou argumentar, na maioria das vezes são vistas pelos professores como agressivas ou pouco femininas. Já os meninos brilhantes que manifestam esses mesmos traços são considerados precoces", ou seja, o que socialmente se permite a uns se proíbe a outros, moldando-os segundo as expectativas de comportamento, apesar das grandes transformações sociais do século passado.

27 WECHSLER, 1993

${ }^{28}$ ALENCAR, 2001.

${ }^{29}$ Maria Lúcia Prado SABATELLA, 2005, p. 95.

516 Estudos Feministas, Florianópolis, 19(2): 503-519, maio-agosto/2011 
Embora quase todos os participantes da presente pesquisa declarassem acreditar que as meninas têm a mesma competência que os meninos, ao serem indagados sobre os motivos de haver um número muito maior de meninos que meninas no Programa, as falas explicativas foram contraditórias. Dois entrevistados apresentaram a normalidade (sic) das meninas como um possível fator que levaria à não indicação dessas para o Programa:

As meninas normalmente já são boas... os meninos, não; então, quando um é bom já é motivo de chamar a atenção, de considerá-lo superdotado. (Professor da sala de recursos)

Quais os significados de bom e boas? O meio social das escolas, tendente ao conformismo, aliado ao magistério predominante ou exclusivamente feminino, pode tornar as meninas boas ou que se adaptam com maior facilidade, enquanto pode tornar o ambiente mais dificilmente suportável para os meninos, que seriam avaliados como não bons. É como uma profecia autorrealizadora:

O normal, o habitual, o que você vê muito é que os meninos não se mostram tanto quanto as meninas no ensino regular. Então aquele que mostra de repente você observa... E aí a menina, talvez, só quando ela faz algo, muito... extraordinário, para poder alguém olhar... (Professor da sala de recursos)

Eu acredito que [a matrícula maior de meninos que meninas no Programa] seja decorrente dessa visão ainda machista... Porque a mulher, às vezes, na timidez dela, fica reclusa e isso impede... O homem, como é mais solto, além de falar mais... e a mulher, a fala dela é mais liberada com a outra coleguinha... (Professor da sala de recursos)

Acho que isso é cultural, né?! A nossa cultura sempre colocou o homem como o que pode tudo... (Professora da sala de recursos)

O menino, ele é mais extrovertido... as meninas ficam "naquela coisa" de educação, mesmo, né? Que tá determinando as coisas que menina faz... O menino tá livre... Acho que é por aí. (Professora do ensino regular)

Por fim, duas participantes entrevistadas, professoras das salas de recursos, se revelaram surpreendidas com o contraste entre a maioria feminina no magistério e a minoria de meninas no Programa:

Por conta dessa visão fechada, míope das professoras... O nosso olhar é focado para o menino, e, quando ele é diferente, aí ele chama a atenção. (Professora da sala de recursos)

Nós somos professoras, deveríamos estar fazendo essa revolução, [mas] a gente está na realidade repetindo isso. (Professora da sala de recursos)

Assim, as entrevistadas apontaram para a transmissão cultural intergeracional e a socialização vertical, em que professoras educadas segundo determinados padrões acabam por socializar a nova geração de acordo com os mesmos moldes. Com isso, os meninos têm oportunidades desiguais no acesso ao Programa, ao passo que as meninas são rotuladas como normais.

\section{Conclusão}

A presente pesquisa objetivou investigar se os sinais manifestos de superdotação são mais detectados nos alunos do que nas alunas e por quê. Conclui-se que, ao se tratar de crianças com altas habilidades/superdotação, as semelhanças entre os gêneros são consideradas mais numerosas pelos profissionais das salas de recursos, ao contrário dos profissionais do ensino regular. Então, por que o número consideravelmente maior de 
meninos no Programa? Esse era o objetivo geral da pesquisa, isto é, identificar, na percepção de professores e outros profissionais, os motivos relacionados à sub-representação feminina. Não foi objetivo da presente pesquisa avaliar se devem ou não ser oferecidos programas específicos para alunos com altas habilidades/superdotação.

Nesse processo de identificação do aluno com altas habilidades/superdotação para posterior encaminhamento, a indicação é feita pelos profissionais do ensino regular, e esses, conforme dados obtidos nesta pesquisa, ratificados por outras investigações, não receberam nenhum tipo de treinamento, instrução ou orientação para procederem à identificação e à seleção dos alunos.

Ao serem solicitados a apontar os critérios utilizados para identificar as características/ comportamentos de superdotação e suas variações por gênero, de acordo com os relatos dos participantes, observou-se que esses critérios são bastante subjetivos, pautados na "observação" e nas "percepções" do professor. Porém, esses profissionais declararam não ter experiência na área, o que leva a indagar em que medida a seleção se baseia no senso comum, sobre o qual incidem preconceitos contra a menina e a mulher. Isso leva a concluir que a indicação/encaminhamento às salas de recursos para superdotados é permeada por vieses estereotipados.

Sugere-se uma reflexão acerca dos estudos sobre as relações sociais de gênero e suas implicações na área da educação, em especial sobre a educação de alunas com altas habilidades, bem como uma mudança de atitudes que envolva a formação dos profissionais que atuam na área; as orientações dadas aos professores do ensino regular, responsáveis pela indicação, e a reestruturação/redefinição dos critérios de seleção desses alunos e alunas, visando a uma melhor adequação da porta de entrada do Programa, com o fim de atender, de forma igualitária, a ambos os gêneros. Caso contrário, profissionais pouco preparados continuarão a abrir a porta para uns e fechá-la para outras.

\section{Referências bibliográficas}

ADAMS, Carol. "Docentes como agentes de mudança". In: SILVEIRA, Maria Lúcia; GODINHO, Tatau. (Org.). Educar para a igualdade: gênero e educação escolar. São Paulo: Secretaria Municipal de Educação, Coordenadoria Especial da Mulher, 2004. p. 117-114.

ALENCAR, Eunice Soriano de. Criatividade e educação de superdotados. Petrópolis: Vozes, 2001.

ALENCAR, Eunice Soriano de; FLEITH, Denise de Souza. Superdotados: determinantes, educação e ajustamento. 2. ed. São Paulo: EPU, 2001.

BARDIN, Laurence. Análise de conteúdo. Lisboa: Edições 70, 1995.

BAUDELOT, Christian; ESTABLET, Roger. Allez les filles! Paris: Éds. du Seuil, 2006.

. Quoi de neuf chez les filles? Entre stéréotypes et libertés. Paris: Nathan, 2007.

BENEVIDES, Maria Vitória. "Cidadania e questão de gênero". In: SILVEIRA, Maria Lúcia; GODINHO, Tatau. (Org.). Educar para a igualdade: gênero e educação escolar. São Paulo: Secretaria Municipal de Educação, Coordenadoria Especial da Mulher, 2004. p. 91-106.

CARVALHO, Marília Pinto de. "Sucesso e fracasso escolar, uma questão de gênero". In: SILVEIRA, Maria Lúcia; GODINHO, Tatau. (Org.). Educar para a igualdade: gênero e educação escolar. São Paulo: Secretaria Municipal de Educação, Coordenadoria Especial da Mulher, 2004. p. 179-192.

FLEITH, Denise de Souza. "Psicologia e educação do superdotado: definição, sistema de identificação e modelo de estimulação". Cadernos de Psicologia da SBP, Ribeirão Preto, v. 5, n. 1, p. 37-50, 1999. 
GOMES, Candido Alberto. A educação em novas perspectivas sociológicas. 4. ed. São Paulo: EPU, 2005.

KERR, Barbara. "Guiding Gifted Girls and Young Women." In: HELLER, Kurt et al. (Org.). International Handbook of Giffedness and Talented. 2. ed. Oxford: Elsevier Science, 2000. p. 649-657.

MAIA-PINTO, Renata Rodrigues. Avaliação das práticas educacionais implementadas em um programa de atendimento a alunos superdotados e talentosos. 2002. Dissertação (Mestrado em Educação) - Universidade de Brasília, Brasília, 2002.

MAIA-PINTO, Renata Rodrigues; FLEITH, Denise de Souza. "Percepção de professores sobre alunos superdotados". Estudos de Psicologia, Campinas, v. 19, n. 1, p. 78-90, 2002.

ORGANIZATION FOR ECONOMIC CO-OPERATION AND DEVELOPMENT. Learning for Tomorrow's World: First Results from PISA 2003. Paris: OECD, 2004. Disponível em: <http:// www.oecd.org/dataoecd/1/60/34002216.pdf>. Acesso em: 28 fev. 2008.

PATON, Michael Quinn. How to Use Qualitative Methods in Evaluation. Newbury Park, Califórnia: Sage, 2000.

POVEY, Hilary. "Dimensões de gênero e desigualdade na escola: o impacto das identidades". In: SILVEIRA, Maria Lúcia; GODINHO, Tatau. (Org.). Educar para a igualdade: gênero e educação escolar. São Paulo: Secretaria Municipal de Educação, Coordenadoria Especial da Mulher, 2004. p. 157-178.

SABATELLA, Maria Lúcia Prado. Talento e superdotação: problema ou solução? Curitiba: Ibpex, 2005.

UNESCO. Relatório global de EPT 2003-2004: educação para todos. Gênero e educação para todos: o salto para a igualdade. São Paulo: Moderna, 2004.

VIRGOLIM, Angela Mágda Rodrigues. Altas habilidades/superdotação: encorajando potenciais. Brasília: Ministério de Educação, Secretaria de Educação Especial, 2007.

WECHSLER, Solange Muglia. Criatividade, descobrindo e encorajando. Campinas: Psy, 1993.

[Recebido em 4 de junho de 2009

e aceito para publicação em 21 de maio de 2010]

Educational Practices Leading to the Reproduction of Inequality: The Underrepresentation of Girls among Gifted Students

Abstract: According to numerous indicators, Brazil and Latin America are very close to reaching the gender equality goal of Education for All. However, a more careful analysis of statistics finds some niches which are unfavourable to girls, since they are perceived by means of prejudice and stereotypes. This is the case of a state educational system in Brazil, where we detected a clear underrepresentation of girls in a program for gifted pupils. The research project aimed to analyze the criteria used for identifying and recommending pupils to enroll in such a program. Based on specifically processed statistics, the researchers selected the geographical area where underrepresentation reached its highest level. Then they conducted semi-structured interviews with schoolteachers as well as with teachers and psychologists of the Program. After that, each participant filled out a checklist of "typical" features and/or behaviours found in giffed girls and boys. Results revealed that schoolteachers underestimated girls' abilities and skills in the process of selection and recommendation for the program. According to interviews, their own negative image of woman partially affects this bias against female pupils. Nevertheless, the Program's teachers and psychologists had a much better understanding on gender inequalities and giftedness, compatible with specialized literature. Therefore, the underrepresentation of girls was a result of a largely biased, subjective selection process and recommendation at schools. As a consequence, teachers need adequate preparation if the educational system maintains the program.

Key Words: Gender; Stereotype; Gifted Students; Special Education. 